\title{
Delayed Hypersensitivity Reaction to Oral Dimethyl Fumarate
}

Antolin-Amerigo D ${ }^{1}$, Sánchez-González $\mathrm{MJ}^{1}$, BarbarrojaEscudero $\mathrm{J}^{1}$, Ayuso-Peralta $\mathrm{L}^{2}$, Bellón-Heredia $\mathrm{T}^{3}$, OrtegaBerruezo MA ${ }^{1}$, Alvarez-Mon $\mathrm{M}^{1}$, Rodríguez-Rodríguez $\mathrm{M}^{1}$ ${ }^{1}$ Servicio de Enfermedades del Sistema Inmune-Alergia, Hospital Universitario Hospital Príncipe de Asturias, Alcalá de Henares, Spain

${ }^{2}$ Servicio de Neurología, Hospital Universitario Hospital Príncipe de Asturias, Alcalá de Henares, Spain

${ }^{3}$ Instituto de Investigación Hospital La Paz, IDIPAZ, Hospital Universitario La Paz, Madrid, Spain

J Investig Allergol Clin Immunol 2018; Vol. 28(3): 201-203 doi: $10.18176 /$ jiaci.0239

Key words: Hypersensitivity. Drug allergy. Multiple sclerosis. Allergy. In vitro technique.

Palabras clave: Hipersensibilidad. Alergia a medicamentos. Esclerosis múltiple. Alergia. Técnica in vitro.

Dimethyl fumarate (DMF) is a molecule derived from fumaric acid that is administered orally for the treatment of relapsing-remitting multiple sclerosis (MS). The mechanism of action of DMF comprises suppression of allergen-induced T-cell proliferation and modulation of the cytokine balance by suppressing only IFN- $\gamma$ and not IL-5 [1-2], thus restoring the $\mathrm{T}_{\mathrm{H}} 1 / \mathrm{T}_{\mathrm{H}} 2$ balance. It is also involved in interference with the intracellular redox balance and activation of nuclear (erythroidderived 2)-like 2 related factor-mediated antioxidative response pathways leading to additional cytoprotective effects, and it seems to exert a marked effect on mitochondria [1-3].

We present the case of a 46-year-old woman with relapsing-remitting MS who had received several treatment options. However, given that she was a frequent traveller, she switched to DMF, which is a convenient, practical, efficacious first-line treatment for MS. Several hours after intake of the first dose of $240 \mathrm{mg}$, she developed generalized confluent and intensely pruritic wheals without angioedema or other systemic symptoms. These were treated at the emergency department with intramuscular methylprednisolone $(60 \mathrm{mg})$ and dexchlorpheniramine $(5 \mathrm{mg})$. She denied having taken NSAIDs, infection, or other possible causes of urticaria and had never experienced urticaria during her lifetime. Following recently published indications [1], we performed a skin prick test (SPT) with DMF at $7 \mu \mathrm{g} / \mathrm{mL}$ and intradermal tests with DMF at $0.7 \mu \mathrm{g} / \mathrm{mL}$ and $0.07 \mu \mathrm{g} / \mathrm{mL}$. The results were negative. We also carried out a lymphocyte transformation test (LTT) using several concentrations: $70 \mu \mathrm{g} / \mathrm{mL}, 35 \mu \mathrm{g} / \mathrm{mL}$, $15 \mu \mathrm{g} / \mathrm{mL}, 7 \mu \mathrm{g} / \mathrm{mL}, 5 \mu \mathrm{g} / \mathrm{mL}, 3.5 \mu \mathrm{g} / \mathrm{mL}, 1 \mu \mathrm{g} / \mathrm{mL}, 0.5 \mu \mathrm{g} /$ $\mathrm{mL}, 0.1 \mu \mathrm{g} / \mathrm{mL}$, and $0.05 \mu \mathrm{g} / \mathrm{mL}$. The results were positive. Phytohemagglutinin A (PHA) as a control mitogen LTT is considered weakly positive or doubtful if the stimulation index (SI) is between 2 and 3 and definitely positive if the SI is $>3$ 
(Table) [4,5]. Moreover, and for the sake of clarity, we also performed LTT on a patient who had tolerated DMF adequately for over 4 months. The results were clearly negative, with slightly positive proliferation at low concentrations of $0.5 \mu \mathrm{g} / \mathrm{mL}$ and $1 \mu \mathrm{g} / \mathrm{mL}$ (all concentrations showed an $\mathrm{SI}<3$ ). Although it would be desirable to study the T-cell response in additional tolerant donors, the weak response in the exposed tolerant donor may reflect the subclinical immune response often detected in patients receiving treatment with various medications [6]. However, and although the slight positivity of the control might indicate a specific reaction, it does not exceed an SI of 3, which is diagnostic in this case.

Interestingly, the LTT was not impaired in the sample of the patient at the different concentrations administered (Table). We believe this result is valid, since the control did not show any significant change at the same DMF concentrations. The mechanism of action of DMF is not completely known. Therefore, although impairment of the in vitro technique is plausible, it is not relevant in the case we report, as can be seen in the results obtained for both the patient and the control.

Additional cell and cytokine data would strengthen the case report; however, the patient migrated to another country, and no further studies could be performed.

Considering that the patient had previously tolerated alternative treatments for MS, she was advised to use subcutaneous glatiramer acetate instead of DMF. Since the clinical response was good, with no significant adverse effects, we did not prescribe desensitization to DMF. Of note, the patient had previously been diagnosed with autoimmune thyroiditis. It seems that the prevalence of other autoimmune disorders is greater in patients with autoimmune thyroiditis, as reported elsewhere [7].

Interestingly, DMF has also been anecdotally reported to relieve asthma symptoms in patients with asthma and psoriasis [8]. In experimental studies, DMF inhibited

Table. Stimulation index

\begin{tabular}{lcc}
\hline & Allergic Patient & Control Patient \\
\hline DMF Concentration & & \\
\hline $70 \mu \mathrm{g} / \mathrm{mL}$ & 0.70 & 0.57 \\
$35 \mu \mathrm{g} / \mathrm{mL}$ & 1.14 & 0.62 \\
$15 \mu \mathrm{g} / \mathrm{mL}$ & 2.19 & 0.58 \\
$7 \mu \mathrm{g} / \mathrm{mL}$ & 2.54 & 0.63 \\
$5 \mu \mathrm{g} / \mathrm{mL}$ & 2.83 & 0.94 \\
$3.5 \mu \mathrm{g} / \mathrm{mL}$ & 3.19 & 1.54 \\
$1 \mu \mathrm{g} / \mathrm{mL}$ & 2.96 & 2.33 \\
$0.5 \mu \mathrm{g} / \mathrm{mL}$ & 2.97 & 2.25 \\
$0.1 \mu \mathrm{g} / \mathrm{mL}$ & 2.48 & 1.54 \\
$0.05 \mu \mathrm{g} / \mathrm{mL}$ & 1.79 & 1.09 \\
\hline Control + & & \\
\hline PHA $(1 \mu \mathrm{g} / \mathrm{mL})$ & 161.92 & 57.33 \\
\hline Background & $94.2 \mathrm{cpm}$ & $102.3 \mathrm{cpm}$ \\
\hline
\end{tabular}

Abbreviations: DMF, dimethyl fumarate; PHA, phytohemagglutinin proliferation and proinflammatory transcription factors, as well as secretion of asthma-relevant cytokines in primary human lung cells. In nickel-allergic patients, DMF has been shown to have a down regulatory effect on $\mathrm{T}_{\mathrm{H}} 1 \mathrm{~T}$ cells, whereas $\mathrm{T}_{\mathrm{H}} 2$ cells were unaffected [1]. Moreover, sensitization DMF has been reported to lead to delayed-type contact dermatitis and contact urticaria to footwear, clothing, and furniture, where it is used as a mold growth inhibitor [9].

DMF was approved as an oral drug in 2013, and, since then, only 1 case of immediate hypersensitivity has been reported [1]. The patient was a 57-year-old woman with MS treated with oral DMF who reported immediate (within minutes) hypersensitivity symptoms, namely, rapid onset of urticaria with confluent wheals and itching 2 days after reaching the twice-daily dose of $240 \mathrm{mg}$. The patient was successfully desensitized. The DMF maintenance dose is usually reached incrementally, the target dose being $240 \mathrm{mg}$ twice a day. The authors left a 7-day washout period and advised the patient to resume DMF (240 mg daily). The patient had an immediate generalized urticarial reaction within a few minutes, suggesting a causative role for DMF, as the authors stated. Subsequent SPT with DMF was negative. LTT with various DMF concentrations was also negative. The authors reached the diagnosis based on the clinical features of the case (time of onset, morphology of the lesions, rapid response to antihistamines). A 40-day stepwise desensitization schedule was successfully completed.

Expression of CXCL10 in serum and/or tissue is increased in organ-specific autoimmune diseases, such as autoimmune thyroiditis, Graves disease, type 1 diabetes, and/or systemic rheumatologic disorders (eg, rheumatoid arthritis, systemic lupus erythematosus, systemic sclerosis, mixed cryoglobulinemia), thus underlining the importance of a common immunopathogenesis characterized by a $\mathrm{T}_{\mathrm{H}} 1$ prevalent autoimmune response [7]. In the present case, the patient seems to have developed a $\mathrm{T}$ lymphocyte-specific response to DMF, which may indicate sensitization to DMF as a possible explanation for her delayed generalized urticaria. We hypothesize that patients with other autoimmune disorders may have an impaired $T_{H} 1 / T_{H} 2$ balance, thus rendering them more prone to adverse drug reactions.

Given that DMF is used as an antifungal agent in shoes and other leather goods, we hypothesize that the patient may have been previously subclinically sensitized to DMF. The symptoms then appeared after ingestion of oral DMF.

We report the first case of delayed hypersensitivity reaction to DMF diagnosed based on clinical findings and LTT results. LTT was useful in identifying the drug responsible for the reaction, namely DMF. Therefore, LTT should be taken into account for assessment of unexpected reactions caused by lymphocytes.

\section{Funding}

This study was partially supported by a grant awarded to TB from Comunidad de Madrid S2010/BMD-2502 MITIC Research grant FIS PI13/01768, Instituto de Salud Carlos III - Ministerio de Economía y Competitividad (cofunded by FEDER). 


\section{Conflicts of Interest}

The authors declare that they have no conflicts of interest.

\section{References}

1. Di Bona D, Albanesi M, Giliberti LA, Nico A, Rossi MP, Caiaffa $M F$, et al. Desensitization for immediate hypersensitivity to oral dimethyl fumarate (Tecfidera). J Allergy Clin Immunol Pract. 2017;5(3):821-2.

2. Linker RA, Gold R. Dimethyl fumarate for treatment of multiple sclerosis: mechanism of action, effectiveness, and side effects. Curr Neurol Neurosci Rep. 2013;13(11):394.

3. Bomprezzi R. Dimethyl fumarate in the treatment of relapsing-remitting multiple sclerosis: an overview. Ther Adv Neurol Disord. 2015;8(1):20-30.

4. Pichler WJ, Tilch J. The lymphocyte transformation test in the diagnosis of drug hypersensitivity. Allergy. 2004;59:809-20.

5. Jurado-Palomo J, Cabañas R, Prior N, Bobolea ID, FiandorRomán AM, López-Serrano MC, et al. Use of the lymphocyte transformation test in the diagnosis of DRESS syndrome induced by ceftriaxone and piperacillin-tazobactam: two case reports. J Investig Allergol Clin Immunol. 2010;20(5):433-6.

6. Qiao HL, Gao N, Jia LJ, Yang J, Tian X. Specific IgG antibodies in sera in patients with penicillin allergy. Clin Exp Med. 2009;9(2):105-11.

7. Fallahi P, Ferrari SM, Ruffilli I, Elia G, Biricotti M, Vita R, et al The association of other autoimmune diseases in patients with autoimmune thyroiditis: Review of the literature and report of a large series of patients. Autoimmun Rev. 2016;15(12):11258.

8. Seidel P, Roth M. Anti-inflammatory dimethylfumarate: a potential new therapy for asthma? Mediators Inflamm. 2013;2013:875403.

9. Stingeni L, Neve D, Tondi V, Bacci M, Lisi P. Immunological contact urticaria caused by dimethyl fumarate. Contact Dermatitis. 2014;71(3):180-3.

Manuscript received November 26, 2017; accepted for publication February 13, 2018.

Darío Antolín-Amerigo Servicio de Enfermedades del Sistema Inmune-Alergia Hospital Universitario Príncipe de Asturias Carretera de Alcalá-Meco s/n 28085 Alcalá de Henares, Spain E-mail: dario.antolin@gmail.com 